\title{
ORIGINAL ARTICLE Retrospective analysis of spinal trauma in patients with ankylosing spondylitis: a descriptive study in Indian population
}

\author{
R Mahajan, HS Chhabra, A Srivastava, R Venkatesh, V Kanagaraju, R Kaul, V Tandon, A Nanda, \\ G Sangondimath and N patel
}

Objective: This study aims to understand the demographics, mode of trauma, hospital stay, complications, neurological improvement, mortality and expenditure incurred by Indian patients with spinal trauma and ankylosing spondylitis (AS).

Methods: Retrospective analysis of the patient data admitted to a tertiary referral hospital from 2008 to 2013 with the diagnosis of AS and spinal trauma was carried out. The variables studied were demographics, mode of trauma, neurological status, neurological improvement, involved vertebral level, duration of hospital stay, comorbid factors, expenditure and complications during the stay.

Results: Forty-six patients with diagnosis of AS with spine trauma were admitted over the last 5 years with a total of 52 fractures. All were male patients; $58.6 \%$ had injury because of trivial trauma and $78.2 \%$ patients presented with neurological injury. C5 C6, C6 C7, C7 D1 and D12 were the most common injured level. Fractures through intervertebral disc were most common in cervical spine. Of the patients, 52.7\% had shown neurological improvement of at least grade 1(AIS). Mean expenditure of patient admitted with spinal cord injury (SCI) with AS is 7957 USD (United States dollar), which is around five times the per capita income in India (as per year 2013). Conclusion: Males with AS are much more prone to spinal fractures than females and its incidence may be higher than previously reported. Domestic falls are the most common mechanism of spinal trauma in this population. High velocity injuries are associated with complete $\mathrm{SCl}$. The study reinforces the need for development of subsidized spinal care services for $\mathrm{SCl}$ management.

Spinal Cord (2015) 53, 353-357; doi:10.1038/sc.2014.150; published online 16 September 2014

\section{INTRODUCTION}

Ankylosing spondylitis (AS) is an inflammatory enthesopathy, which affects the axial joints of the body. It results in bamboo spine, which may result in disabling kyphotic spinal deformity. This can lead to compromised forward gaze and sagittal imbalance, thereby predisposing them to frequent falls. Moreover, the systemic and metabolic effects of the disease make the spine osteoporotic and brittle. This contributes to four to five times increased frequency of spinal fractures in them as compared with the general population. ${ }^{1}$ Currently, surgery is the preferred method to stabilize these injuries to promote early mobility and prevent chest complications. However, they have increased tendency to experience postoperative complications as evident from published western studies, because of extensive restrictive lung disease, other comorbidities and complexity of the surgical procedure itself. Further, the incidence of neurological involvement after fracture and, consequently, the burden of the spinal cord injury (SCI) are higher, which puts strain on the family as well as public resources especially in the developing countries. In addition to above, AS also has ethnic and regional variations, which can impact disease presentation and management. ${ }^{2}$ Unlike the western world, the public health system in India is underfunded, strained and health insurance coverage is minimal, compounding the situation further. ${ }^{3}$ The care of spinal trauma is all the more compromised in this part of this world because of very few spinal injury rehabilitation centers. ${ }^{4}$ There is a lot less data from developing countries on spinal trauma in AS patients.
This stresses the need for a study that focusses on a developing country like India, which houses one-sixth of the world's population.

\section{MATERIALS AND METHODS}

We retrospectively analyzed data of patients admitted and managed with the diagnosis of AS with spinal fractures at our institution for the last 5 years (2008-2013). Our institution is one of the main referral centers for the spinal cord trauma and injury in India. All patient files were retrospectively studied and parameters such as age, sex, diagnosis, mode of trauma, neurological status, neurological recovery, operative procedure carried out, complications, comorbidities, length of hospital stay and hospital expenses incurred by the patient were noted. The cost was calculated in Indian Rupees (INR) and then converted to US dollar (1 USD $=60$ INR approximatly), for ease of comparison. Data were also analyzed to determine the most common level of fracture in AS patients. Comorbidities like diabetes, hypertension (HT), cardiovascular disease, cerebrovascular disease, chronic liver disease and chronic lung disease were also recorded to identify any significant association with AS. Complications such as wound infection, implant failure, chest complications, skin complications, neurologic deterioration after surgery, deep vein thrombosis, pulmonary embolism, sepsis and death were noted. The data were tabulated in an excel sheet, and mean, median and relevant data were recorded.

\section{RESULTS}

All 46 patients who presented with diagnosis of spinal trauma with AS were male patients (Table 1). Mean age of the patients was 58.72 years (range $38-72$, s.d. \pm 13.23 ). Of the patients, $58.6 \%$ had a history of 
Table 1 Demographics of 46 patients with ankylosing spondylitis

\begin{tabular}{|c|c|c|c|c|c|c|}
\hline Patients & Age & Sex & $\begin{array}{c}\text { Fracture } \\
\text { level }\end{array}$ & $\begin{array}{c}\text { AIS } \\
\text { neurology }\end{array}$ & Expired & $\begin{array}{c}\text { High }(H) \text { vs low } \\
\text { (L) mode of } \\
\text { trauma }\end{array}$ \\
\hline Case 1 & 51 & $\mathrm{M}$ & C3C4 & A & & $\mathrm{H}$ \\
\hline Case 2 & 80 & M & D10 & A & Expired & $\mathrm{H}$ \\
\hline Case 3 & 82 & $M$ & L1 & A & Expired & L \\
\hline Case 4 & 38 & $\mathrm{M}$ & C7D1, D8D9 & E & & $\mathrm{H}$ \\
\hline Case 5 & 58 & $M$ & $\mathrm{C} 7$ & E & & L \\
\hline Case 6 & 74 & M & D5D6 & C & & $\mathrm{H}$ \\
\hline Case 7 & 39 & $M$ & D4 & E & & L \\
\hline Case 8 & 49 & $M$ & L1 & D & Expired & L \\
\hline Case 9 & 50 & $\mathrm{M}$ & D12 & E & & $\begin{array}{c}\text { Trauma not } \\
\text { noticed }\end{array}$ \\
\hline Case 10 & 55 & $M$ & L3L4 & E & & $\begin{array}{c}\text { Trauma not } \\
\text { noticed }\end{array}$ \\
\hline Case 11 & 53 & $M$ & $\mathrm{C7}$ & E & & L \\
\hline Case 12 & 53 & $\mathrm{M}$ & D10D11 & E & & L \\
\hline Case 13 & 59 & $M$ & $\mathrm{C} 6 \mathrm{C7}$ & D & & L \\
\hline Case 14 & 46 & $M$ & D8D9 & D & & L \\
\hline Case 15 & 50 & $M$ & C5C6 & E & & L \\
\hline Case 16 & 68 & $M$ & $\mathrm{C} 6 \mathrm{C} 7$ & D & & L \\
\hline Case 17 & 68 & $M$ & c5c6 & C & & $\mathrm{H}$ \\
\hline Case 18 & 65 & $M$ & D12L1 & D & & L \\
\hline Case 19 & 52 & $\mathrm{M}$ & D11D12 & D & & L \\
\hline Case 20 & 63 & $\mathrm{M}$ & D12 & A & & $\begin{array}{c}\text { Trauma not } \\
\text { noticed }\end{array}$ \\
\hline Case 21 & 38 & $M$ & $\mathrm{C} 4 \mathrm{C} 5, \mathrm{C} 6 \mathrm{C} 7$ & B & Expired & $\mathrm{H}$ \\
\hline Case 22 & 82 & $\mathrm{M}$ & D12L1 & E & & $\mathrm{H}$ \\
\hline Case 23 & 74 & $M$ & $\mathrm{C} 3 \mathrm{C} 4$ & C & & $\mathrm{H}$ \\
\hline Case 24 & 44 & $\mathrm{M}$ & $\mathrm{D} 12$ & A & & $\mathrm{H}$ \\
\hline Case 25 & 49 & M & $\mathrm{C5}$ & $\mathrm{E}$ & & L \\
\hline Case 26 & 70 & $\mathrm{M}$ & D8D9 & B & & L \\
\hline Case 27 & 49 & $M$ & C5C6 & C & & L \\
\hline Case 28 & 41 & $M$ & L1L2 & B & & L \\
\hline Case 29 & 52 & $M$ & $\mathrm{C} 6$ & C & & $\mathrm{H}$ \\
\hline Case 30 & 61 & $\mathrm{M}$ & $\mathrm{C} 6 \mathrm{C7}$ & B & & $\mathrm{H}$ \\
\hline Case 31 & 72 & $M$ & D9D10 & D & & $\begin{array}{c}\text { Trauma not } \\
\text { noticed }\end{array}$ \\
\hline Case 32 & 68 & $M$ & D12 & C & & $\mathrm{L}$ \\
\hline Case 33 & 80 & $M$ & $\mathrm{C} 5 \mathrm{C} 6$ & D & & L \\
\hline Case 34 & 81 & $M$ & $\mathrm{C6}$ & C & & L \\
\hline Case 35 & 75 & M & L1 & A & & L \\
\hline Case 36 & 65 & $M$ & $\mathrm{C} 6 \mathrm{C} 7$ & D & & L \\
\hline Case 37 & 47 & $M$ & D11D12 & A & & L \\
\hline Case 38 & 53 & $\mathrm{M}$ & D5D6 & A & & $\mathrm{H}$ \\
\hline Case 39 & 64 & $M$ & C7D1, D8 & A & & L \\
\hline Case 40 & 48 & $M$ & $\mathrm{C} 2, \mathrm{C} 5$ & C & & L \\
\hline Case 41 & 50 & $M$ & C7D1 & C & Expired & L \\
\hline Case 42 & 34 & M & $\begin{array}{l}\text { C7 D1, D9 } \\
\text { D10 L2 L3 }\end{array}$ & A & & $\mathrm{H}$ \\
\hline Case 43 & 78 & $M$ & D10 & D & & L \\
\hline Case 44 & 54 & $M$ & $\mathrm{C5C6}$ & A & & $\mathrm{H}$ \\
\hline Case 45 & 58 & $M$ & C7D1 & B & & $\mathrm{L}$ \\
\hline Case 46 & 61 & M & D12 & A & & $\mathrm{H}$ \\
\hline
\end{tabular}

trivial trauma, out of which majority had a fall at home; $78.2 \%$ presented with neurological deficit; $54.3 \%$ presented with incomplete SCI (ASIA impairment scale (AIS) B, C, D). Mean number of days of stay in hospital were 34 days (s.d. 49.13 days). Mean expenditure incurred by patient in hospital was 7957 USD (s.d. 7088, range
Table 2 Comorbidities in AS patients with spine trauma

\begin{tabular}{lrr}
\hline & Comorbidities \\
\hline Hypertension & 18 & \\
Diabetes & 12 & \\
Cardiac disease & 7 & Total number of patients with any \\
Moderate or severe liver disease & 1 & comorbidity $=22$ \\
Cerebrovascular & 1 & \\
Chronic lung disease & 2 & \\
\hline
\end{tabular}

Table 3 Complications in operated AS patients with spine trauma

\begin{tabular}{ll}
\hline Comorbidities & $n$ \\
\hline Pressure sore & 4 \\
Chest complications & 8 \\
Infection & 5 \\
Implant failure & 2 \\
Pulmonary embolism & 1 \\
DVT & 1 \\
Septicemia & 1 \\
Neurologic deterioration & 1 \\
\hline
\end{tabular}

Abbreviations: AS, ankylosing spondylitis; DVT, deep vein thrombosis.

192-29 837). Of the patients, $47.8 \%$ had one or more comorbidities (Table 2). HT was the most common comorbidity identified in $39.1 \%$ of patients. It was followed by type 2 diabetes mellitus that was present in $26 \%$ of the patients. Chest complications $(17.3 \%)$ were the most frequent complications, which occurred in the postoperative period. Postoperative infection was present in $10.8 \%$ of patients. Pressure sores were present in $8.6 \%$ of patients. Implant failure occurred in two patients. One patient had deep vein thrombosis and one patient developed pulmonary embolism. In one patient, neurology deteriorated postoperatively (Table 3). Overall, there were 52 fractures in 46 patients. Thirty-three fractures $(63.4 \%)$ were through the intervertebral discs whereas 19 fractures $(36.5 \%)$ occurred through the vertebral body (Table 4). Fractures through disc were more common in cervical spine (18/25). Most common level of fracture were C5C6, C6C7, C7D1 and D12 each contributing five fractures. Five patients had fracture at more than one level. Four patients had fractures at two levels at the time of initial presentation, whereas one patient had fracture at three levels in spinal column. Of the patients, $52.7 \%$ had shown neurological improvement of at least one AIS grade by the last follow-up. None of AIS A had recovered whereas all AIS D had become AIS E by last follow-up. Two patients with AIS B had shown neurological improvement by grade one. Seven patients with AIS C had shown grade 1 improvement. Five patients had expired until the last follow-up.

\section{DISCUSSION}

AS with SCI is a disabling condition with increased mortality and morbidity as compared with the normal population. ${ }^{5}$ To the best of the author's knowledge, the current series is the second largest series of operated cases of AS patients with spinal trauma in published literature and the largest of Indian patients (Table 5). Caron et al. ${ }^{6}$ have reported a series comprising 112 patients but 78 of them were diffuse idiopathic skeletal hyperostosis (DISH) and 28 were only of AS. AS has been known to affect males more than females for a long time. 
Table 4 Distribution of fracture at vertebral level and disc in patients with AS

\begin{tabular}{lc}
\hline Fracture level & No. of fractures \\
\hline C2 & 1 \\
C3C4 & 2 \\
C4C5 & 1 \\
C5 & 2 \\
C5C6 & 5 \\
C6 & 2 \\
C6C7 & 2 \\
C7 & 5 \\
C7D1 & 2 \\
D4 & 5 \\
D5D6 & 5 \\
D8 & 1 \\
D8D9 & 2 \\
D9D10 & 1 \\
D10 & 3 \\
D10D11 & 3 \\
D11 D12 & 2 \\
D12 & 2 \\
D12 L1 & 2 \\
L1 & 2 \\
L1L2 & 2 \\
L2L3 & 2 \\
L3L4 & 2 \\
\hline
\end{tabular}

Abbreviation: AS, ankylosing spondylitis.

Initially, the described ratio was $10: 1$, though with time most scholars agree to a ratio much lower around 2:1. ${ }^{7}$ Aggarwal et al. describe the prevalence of AS in Indian population and found it to be $5: 1{ }^{8}$ Westerveld et al. ${ }^{5}$ had carried out a meta-analysis in 2009 in which 345 AS patients with spinal fractures were included in the study. The male-to-female ratio was 9:1. This ratio is much higher than the prevalence of AS in general population. In contrast to their observation, our study did not have any females. It suggests and possibly emphasizes that spinal affection in AS is more severe in Indian males as compared with females, which may make them more vulnerable to spinal column injury. No series in literature has depicted such strong male association in AS with spinal fracture so far. Other possibility that needs to be taken into account is that males as such have more incidence of SCI than females (ratio 6:1). ${ }^{9}$ This factor along with the propensity of AS to preferentially affect males multiplies this association and may be the reason of the presence of only male population in our study.

The average age in our series was found to be 58.71 years (34-82 years) which when compared with other two large series shows that the Indian population was affected almost a decade earlier as compared to the western population. ${ }^{6,10}$ However, Westerveld et al. ${ }^{5}$ in a meta-analysis reported mean age comparable with that of current series of Indian population. However, this meta-analysis has not taken into account two large series of Caron et al. ${ }^{6}$ and Backhaus et al. ${ }^{10}$ from western population which were published later than the Westerveld study. Spine is affected to the same degree in AS in Indians as compared with western counterparts. ${ }^{8}$ This earlier age presentation of spinal fractures in AS may be attributed to increased osteoporosis in Indians as compared with western counterpart because of decreased bone mass, low levels of vitamin $\mathrm{D}$ and poor nutritional status. ${ }^{11}$
Out of 46 patients, 5 had expired until the last follow-up. The demise of three patients was in the hospital setting during the period following the surgery, whereas other two died after 6 months of discharge at home. The overall mortality in our series is low (10.8\%) as compared with 32 and $23 \%$ in other two large published series. ${ }^{6,10}$ It can perhaps be explained by the fact that pre-operative comorbidity in Indian patients is lower as compared with their western counterparts ( 47.8 vs $84 \%$ reported by Caron et al. $\left.{ }^{6}\right)$. This can impact the postoperative recovery period and also can possibly lead to lower mortality rate in the postoperative period. However, this has to be interpreted with caution because of our variable follow-up duration (6 months-5 years) when compared with other series, which may potentially underestimate the mortality figures.

AS patients are at an increased risk of cardiovascular events than the general population. ${ }^{12}$ The most common comorbidity in the Indian population was found to be HT (39.1\%) followed by type 2 diabetes mellitus (26\%). Of the patients, $47.8 \%$ had at least one comorbidity. This observation is in line with the findings of Caron et al. ${ }^{6}$ who also reported HT as the most frequently associated comorbidity (41\%). Most common complication in our series was chest complication $(17.3 \%)$ followed by postoperative wound infection (10.8\%) and pressure sores $(8.69 \%)$.

Twenty-seven patients (58.6\%) had a history of low velocity trauma. In four patients $(8.6 \%)$, trauma was not remembered by the patient and the main complaint was worsening back pain. High velocity injury was present in 15 patients (32.6\%). It was caused by vehicular collision in 14 patients, and in 1 patient, a history of attack by bull was present. This is concordant with most studies, which show low velocity injuries to be the cause of neurologic injuries in AS patients. ${ }^{5,6,10}$ Simple preventive measures at home may result in significant decline in traumatic fractures in this subgroup of population.

Of the patients, $78.2 \%$ presented with neurological deficit (AIS A, B, C, D); $52.17 \%$ presented with incomplete SCI (AIS B, C, D), whereas $26 \%$ (12 patients) had complete SCI (AIS A) (Figure 1); $21.7 \%$ had intact neurology at presentation (AIS E). It was observed that out of 12 complete injuries, eight patients had high velocity injury. This brings out an important fact in our study that in AS though the main modality of trauma is domestic falls at home, most of them result in incomplete injuries whereas complete injuries are usually associated with high velocity trauma.

Fractures through intervertebral disc are common in AS. Of the fractures, $63.4 \%$ occurred through intervertebral discs. Region-wise cervical spine had $72 \%$ of fractures occurring through the disc followed by $57 \%$ and $50 \%$ in dorsal spine and lumbar spine, respectively.

Most of the patients were fused by principal single anterior (mostly cervical) or posterior approach (thoracic and lumbar). Seventeen patients were fused globally, that is, both anterior and posterior. Ten patients (out of 17) with fractures at junctional areas, that is, cervicothoracic and thoracolumbar were fused globally. With modern instrumentation, most fractures in AS can be dealt by a single approach. However, in author's experience, sometimes, especially at junctional regions like C7 D1, a combined approach may be required to prevent instrumentation failure. However, further research is required before drawing definite conclusions.

In India, public sector health care is underfunded and overstretched. In addition, the penetration of health insurance is minimal usually with inadequate financial cover. ${ }^{3}$ Therefore, in devastating injuries like spinal fractures in AS, the cost of health care is borne by patients often by personal loans, savings and sometimes by liquidating the assets. In our study, a patient with AS with spinal fracture spent 


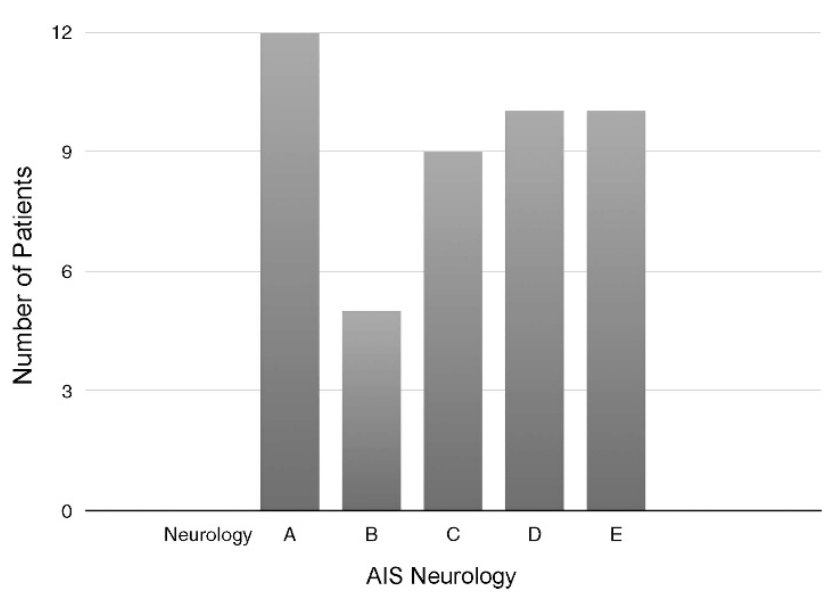

Figure 1 Distribution of patients according to their neurological status.

Table 6 Average expenses incurred to the patients as per their neurological status

\begin{tabular}{lcc}
\hline Neurology & Patients & Average USD spent \\
\hline A & 12 & 10486 \\
B & 5 & 7891 \\
C & 9 & 7903 \\
D & 10 & 8228 \\
E & 10 & 4733 \\
\hline
\end{tabular}

7957 USD for surgery and rehabilitation. Patients with complete SCI with AS spends around 10500 USD (Table 6). It can be explained by the fact that patients with complete SCI stay longer for an average of 58 days in the hospital (including rehabilitation) against an average of 34 days in our study. In India, the per capita income is 1570 USD (2013). Many patients end up selling their resources for spending on medical treatment. Our study is the first to calculate the impact of economic burden after SCI in AS patients. There are also no studies that ascertain the economic impact of SCI in patients in India to the best of our knowledge. Most studies carried out until now are from the western world. This is a study carried out from a single center and more studies need to be carried out from this part of the world. This study brings out the glaring gap in income and medical expenses incurred by a patient after spinal injuries in developing countries like India. The health policy makers should consider these data for devising public health measures and the care providers should also counsel the patient of the financial implications. The patients afflicted by this condition can optimize their health-care insurance and finances to meet the expenses in the event of eventuality.

\section{CONCLUSION}

Males with AS with SCI are much more to prone to spinal fractures as compared with females. Ratio may be higher than that reported in literature. Fractures through intervertebral discs are more common in cervical spine than through dorsal and lumbar spine. Most trauma in AS are due to domestic falls and result in incomplete injuries. Simple prevention measures at home may result in a significant decline in traumatic fractures in this subgroup of population. Complete injuries are more commonly associated with high velocity injuries. HT was the most common comorbidity. Average expenditure of patient admitted for SCI with AS was around 8000 USD, which is 
around five times more than the per capita income of the Indian population. It is the need of the hour to build more spine trauma centers and rehabilitation units across the country where dedicated and affordable patient care can be easily achieved.

\section{DATA ARCHIVING}

There were no data to deposit.

\section{CONFLICT OF INTEREST}

The authors declare no conflict of interest.

1 Jacobs WB, Fehlings MG. Ankylosing spondylitis and spinal cord injury: origin, incidence, management, and avoidance. Neurosurg Focus 2008; 24: E12.

2 Gran JT, Husby G. The epidemiology of ankylosing spondylitis. Semin Arthritis Rheum 1993; 22: 319-334.

3 Dutta M, Husain Z. Does health insurance ensure equitable health outcomes? An analysis of hospital services usage in urban India. World Health Popul 2013; 14: 38-50.
4 Chhabra HS, Arora M. Neglected traumatic spinal cord injuries: causes, consequences and outcomes in an Indian setting. Spinal Cord 2013; 51: 238-244.

5 Westerveld LA, Verlaan JJ, Oner FC. Spinal fractures in patients with ankylosing spinal disorders: a systematic review of the literature on treatment, neurological status and complications. Eur Spine J 2009; 18: 145-156.

6 Caron T, Bransford R, Nguyen Q, Agel J, Chapman J, Bellabarba C. Spine fractures in patients with ankylosing spinal disorders. Spine 2010; 35: 458-464.

7 Feldtkeller E, Khan MA, van der Heijde D, van der Linden S, Braun J. Age at disease onset and diagnosis delay in HLA-B27 negative vs. positive patients with ankylosing spondylitis. Rheumatol Int 2003; 23: 61-66.

8 Aggarwal R, Malaviya AN. Clinical characteristics of patients with ankylosing spondylitis in India. Clin Rheumatol 2009; 28: 1199-1205.

9 Chhabra HS, Arora M. Demographic profile of traumatic spinal cord injuries admitted at Indian Spinal Injuries Centre with special emphasis on mode of injury: a retrospective study. Spinal Cord 2012; 50: 745-754.

10 Backhaus M, Citak M, Kälicke T, Sobottke R, Russe O, Meindl R et al. Spine fractures in patients with ankylosing spondylitis: an analysis of 129 fractures after surgical treatment. Orthopade 2011; 40: 917-920-922-924.

11 Malhotra N, Mithal A. Osteoporosis in Indians. Indian J Med Res 2008; 127: 263-268.

12 Han C, obinson DW Jr, Hackett MV, Paramore LC, Fraeman KH, Bala MV. Cardiovascular disease and risk factors in patients with rheumatoid arthritis, psoriatic arthritis, and ankylosing spondylitis. J Rheumatol 2006; 33: 2167-2172. 